\title{
A Gas Monitoring and Control System in a Coal and Gas Outburst Laboratory
}

\author{
W. Nie, ${ }^{1}$ Y. Liu, ${ }^{1}$ C. J. Li, ${ }^{2}$ and J. Xu ${ }^{1}$ \\ ${ }^{1}$ State Key Laboratory of Coal Mine Disaster Dynamics and Control, Chongqing University, Chongqing 400044, China \\ ${ }^{2}$ Faculty of Resources \& Safety Engineering, China University of Mining \& Technology, Beijing 100083, China
}

Correspondence should be addressed to W. Nie; niewen1026@gmail.com

Received 28 May 2014; Revised 21 July 2014; Accepted 23 July 2014; Published 19 August 2014

Academic Editor: Jesus Corres

Copyright ( $) 2014$ W. Nie et al. This is an open access article distributed under the Creative Commons Attribution License, which permits unrestricted use, distribution, and reproduction in any medium, provided the original work is properly cited.

Coal and gas outburst is a phenomenon characterized by the ejection of gas and coal from the solid face of a mine. Physical minioutburst experiments are a very important tool for analyzing outbursts of coal and gas. However, few reports have focused on the safety problem produced by gas concentration or the role of gas spread during the physical experiments. In this study, we designed a simple monitoring and control system for the safety of staff during the minioutburst experiments. The results showed that, in the simulation of four dangerous situations, the system based on a sensors feedback loop can monitor the development of gas content in the temporal and spatial domains for the enhancement of accurate warnings. The system also automatically chooses the appropriate ventilation measures to lower the gas content considering different degrees of danger.

\section{Introduction}

An outburst of coal and gas is defined as the rapid release of a large quantity of gas in conjunction with the ejection of coal from the solid face. With an increase in mining depth and production, the intensity and frequency of outbursts tend to increase. Physical experiments are a very important tool for analyzing outbursts of coal and gas. In 1953, two Russian researchers announced the first rock and gas minioutburst conducted under laboratory conditions [1]. Shortly after, other researchers started similar experiments incorporating coal briquettes and enhancing the experimental setups and procedures [2-7]. The present work belongs to the same line of research and follows the approach above [8-12]. During the physical experiments, potential hazards from gas concentration for staff have to be emphasized. On preparing the experiments, in case of a gas leak the general method used is to install gas sensor probes mounted in the laboratory such as fiber methane gas sensors to monitor the gas concentration. When the gas leak achieves the prethreshold, the alarm system is activated [13-16]. But a simple method of monitoring could bring the first challenge: (1) the discontinuity of work because of a gas leak: after the beginning of the experiment, the general protective measure used is to keep the staff far away from the experimental devices until the gas totally disappears, which may even take several days, which can be considered as the second challenge; that is, (2) lower experimental efficiency induced by the lack of a powerful gas discharge system: more importantly, the results from the minioutburst experiments are always reported in format of the quantity and distribution of coal in a gas outburst under altered conditions by changing the gas pressure, coal power sizes, and outside loads; the third challenge (3), the role of gas spread, is rarely reported as a result of the lack of gas monitoring systems for collecting the gas concentration trend, which limits the value of miniexperiments. In order to solve the challenges above, in this study we aim to design a simple monitoring and control system to achieve the safety of staff, high work efficiency, and investigation of gas trends during minioutburst experiments [17]. The system not only utilizes sensors to monitor the progress of gas content in temporal and spatial scenes, but also, for different degrees of danger, automatically chooses the appropriate ventilation measures to reduce the increasing gas content in order to improve work efficiency (Figure 1). The remainder of the paper is organized as follows. Section 2 introduces the minioutburst simulation procedure and gas-related issues. 


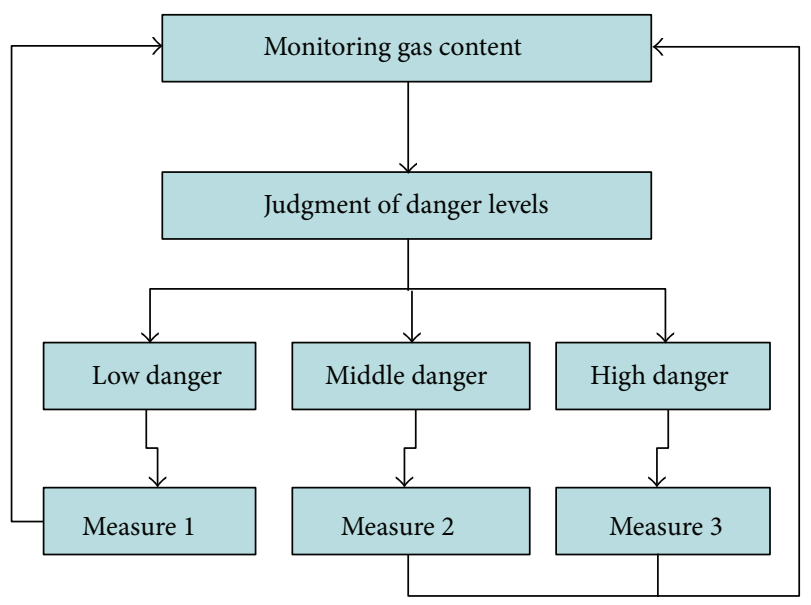

Figure 1: Core idea of this system.

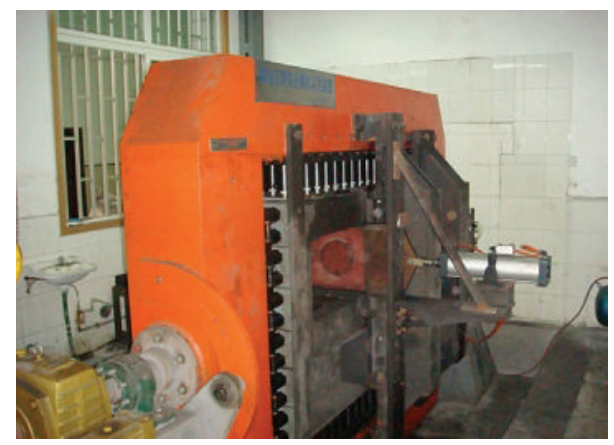

Figure 2: Large-scale simulation test system of coal and gas outburst.

Section 3 highlights the design of the monitoring and control system. The performance of this system involving four different danger levels is introduced and discussed in Section 4. The conclusions and future research directions are detailed in Section 5.

\section{Minioutbursts in Coal and Gas Experiments}

Coal and gas outbursts with certain stress regimes, gas pressures, and material properties of samples are simulated by a coal and gas outburst simulation device consisting of fast-releasing components, a load-bearing frame, electric selfcontrolled loading system, reversal unit, main frame bracket, and coal sample molding device as shown in Figures 2 and 3 [18]. Raw coal was crushed, screened, and compressionmolded to produce standardized samples (briquettes) under $4 \mathrm{MPa}$ of pressure (Figure 4(a)). Seals were installed between the mold and cover before lifting and pasting the mold sealing plate (Figure 4(c)). Then coal samples were filled with gas through pressurization in an airtight box (Figure 4(b)). Before that an airtightness test was required for the gas injection due to the $99.99 \%$ purity of the experimental gas. Air extraction from a vacuum needs to be carried out for about $2 \mathrm{hr}$ before the gas enters. After the gas entered the coal samples, full absorption of gas (about $48 \mathrm{hr}$ ) was the key

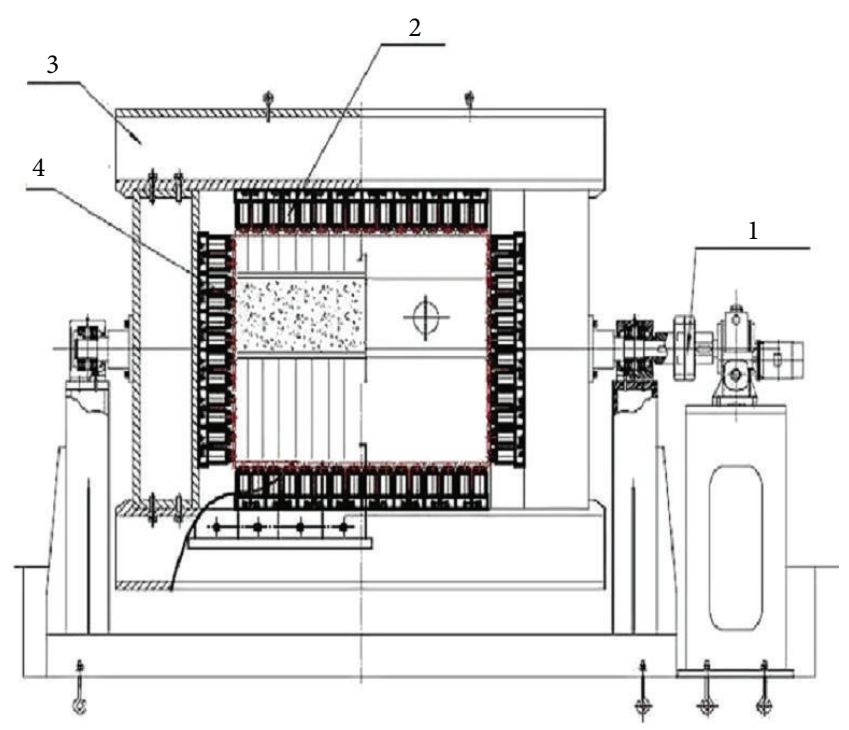

FIGURE 3: Structure of coal and gas outburst simulation test-bed. 1: revolving gear; 2: hydrostatic trigger; 3: bearing frame; 4: coal body.

step in the experiment. The gas pressure can be adjusted by a device during the gas absorption. After that, as shown in Figure 4(b), the horizontal load is added firstly at outburst caliber (P1). The purpose is to prevent the deformation of the coal sample near the outburst caliber. Then the vertical loads P2, P3, and P4 are applied in order. Finally, in order to keep the 3D stress stability, another horizontal load P5 is added facing the outburst caliber on the other side (for more details see [19]). The outburst of coal and gas in the experiment is observed by opening the caliber rapidly. The environmental temperature fluctuates between 18 and $20^{\circ} \mathrm{C}$. The whole procedure is illustrated in Figure 5. As mentioned before, from the gas injection until the beginning of the experiment, Challenge 1 needs to be overcome. Thus, the area around the device is defined as an "unsafe zone." After the beginning of the experiment, the unsafe zone is enlarged to the whole laboratory. Furthermore, Challenge 3 of tracking the gas spread for the coal and gas outburst needs to be dealt with.

\section{Design of the Monitoring and Control System}

3.1. Control Principles. The system utilizes the closed-loop control principle for swift feedback, which means that the subject of study has a feedback loop from the output, through the detector, and back into the input. This improves the robustness of the control system by reducing bias after comparing the output to the initial value, as shown in Figure 6. Figure 7 shows the structure of the closed-loop control system. The sensors detect the current gas content and change the physical signals into electrical signals through a data logger. The computer calculates the difference between the initial gas concentration as input and electrical signals obtained by a data logger. Then the system makes a judgment 


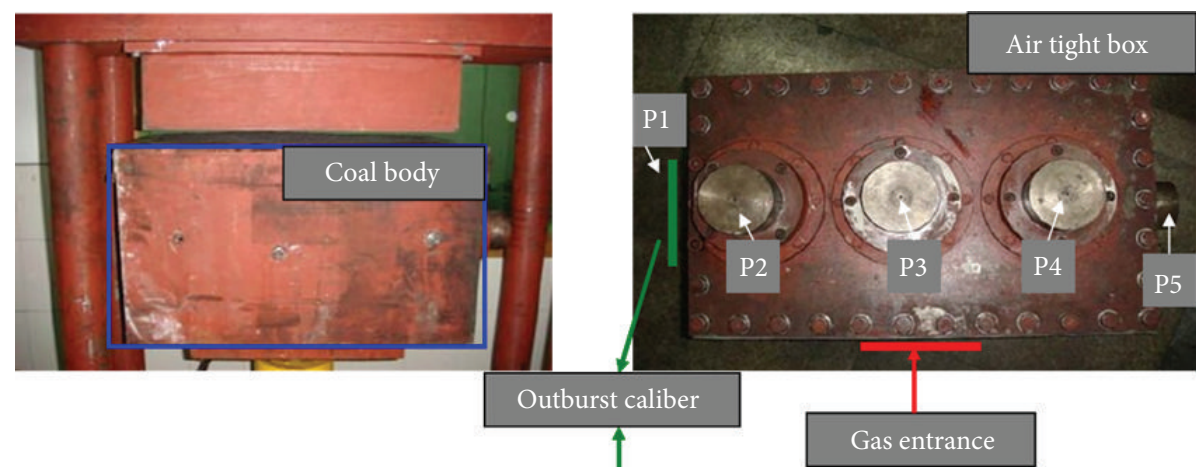

(a)

(b)

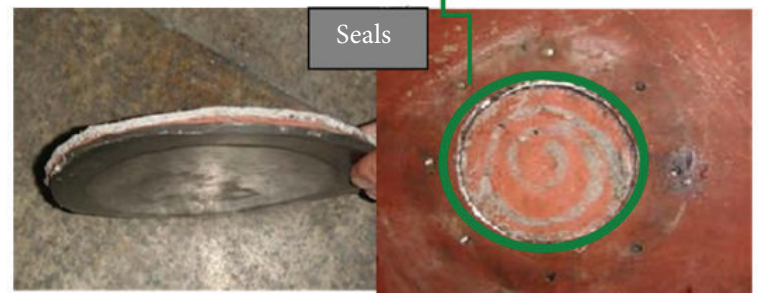

(c)

FIGURE 4: Key components: (a) compression-mold, (b) airtight box, (c) and seals.

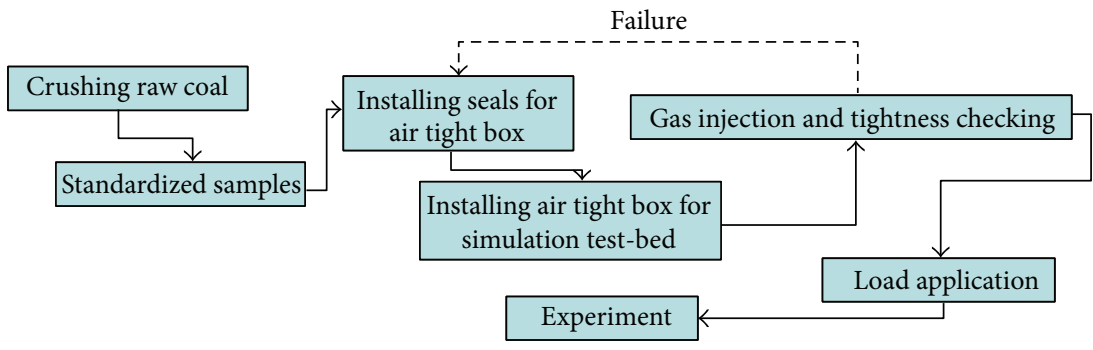

FIGURE 5: Flowchart of simulation test of coal and gas outburst.

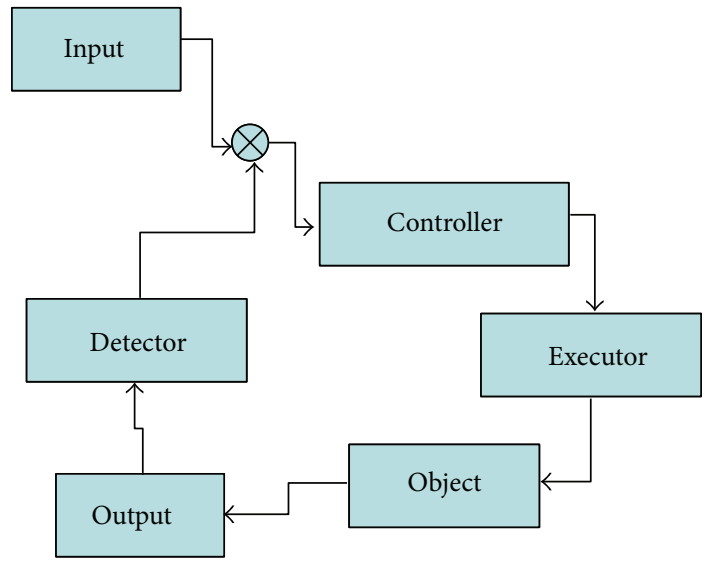

Figure 6: Schematic diagram of the system.

and takes corresponding measures (activates the fans). At any time, the gas content is monitored by sensors and the data logger always introduces the newest data into a cycle.

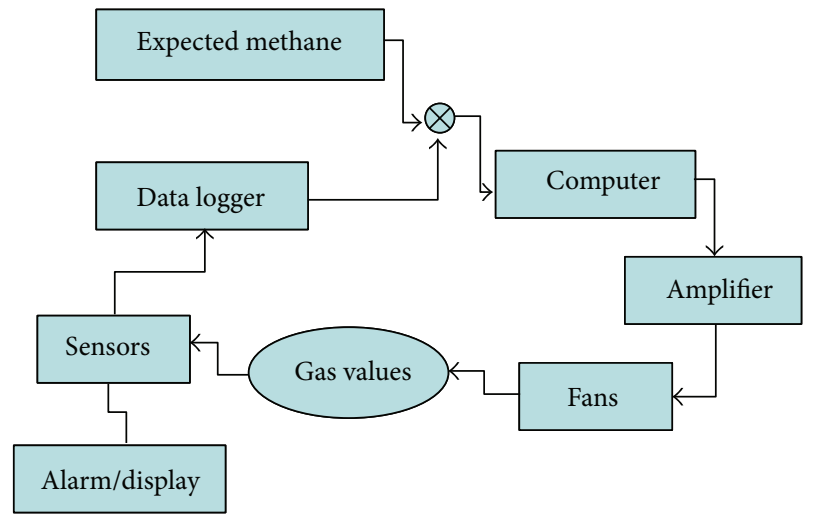

FIGURE 7: Structure chart of closed-loop control system.

3.2. Sensors and Threshold Values. Two methane sensors (Prime 1) which use the nondispersive infrared method to detect the presence of hydrocarbon gases were implemented to monitor the air environment by providing measurements 
TABLE 1: Gas threshold and measures.

\begin{tabular}{lcccc}
\hline Degree of risk & Sensor & Gas content threshold & Measure & Monitoring area \\
\hline Normal & 1,2 & $\mathrm{CH}_{4} \leq 0.025 \%$ & No measure & Entire laboratory \\
Danger 1 & 1 & $\mathrm{CH}_{4}=0.025 \%$ & Attention and Ventilation 1 & Unsafe zone \\
Danger 2 & 1 & $\mathrm{CH}_{4}=1 \%$ & Alarm and Ventilation 2 & Unsafe zone \\
Danger 3 & 2 & $\mathrm{CH}_{4}=0.025 \%$ & Alarm and Ventilation 3 & Entire laboratory \\
Danger 4 & 2 & $\mathrm{CH}_{4}=1 \%$ & Power off and evacuation & Entire laboratory \\
\hline
\end{tabular}

of methane with a resolution of $0.01 \%$ for $0-10 \%$ methane volume. The sensor contains an infrared radiation source, a dual element custom infrared detector, a unique optical waveguide into which gas diffuses, and internal ARM7 core microprocessor based electronics to provide a voltage output which is independent of the power supply polarity. The sensors can be configured to provide a pellistor format output, typically midsupply at zero with the voltage output increasing with respect to the detector pin by $100 \mathrm{mV}$ over the range, or a linear voltage output, typically $0.4-2.0 \mathrm{~V}$ over the range with respect to the negative supply pin. In addition, the output can be read and the internal configuration can be accessed by a serial communications link. Prime 1 is temperature-compensated for both zero and span at the calibration gas concentration level, which is from -20 to $+50^{\circ} \mathrm{C}$. The accuracy is $< \pm 3 \%$ of the range up to $50 \%$ of the range. An all-metal construction with isolated housing was used for the realization of the electrical insulation. An unsafe zone could appear around the simulation device as shown in Figure 8. Sensor 1 is mounted on the edge of the zone. Accounting for the height of the respiratory organs, the location is at $1.7 \mathrm{~m}$ above the ground. The staff could come into contact with methane gas when entering the laboratory from the control room. Thus, Sensor 2 is at the door between the control room and the laboratory at a height of $1.7 \mathrm{~m}$. Gas concentration values of less than $0.025 \%$ rarely hurt the human body. So, under this level, no measures appear. If the gas concentration is between 0.025 and $1 \%$ around the simulation device, it causes a decline in oxygen, which will affect the staff physically and mentally (Danger 1). Danger 2 is defined as a gas concentration level of $1 \%$ based on the Chinese government standard [20]. At Danger 3 during the experiments, Sensor 2 is more reliable as the main monitoring device. The threshold of $0.025 \%$ is different from the $0.025 \%$ level at Danger 1 of Sensor 1. Danger 4 appears if the gas value is higher than $1 \%$ according to Sensor 2 (corresponding to almost $4 \%$ on Sensor 1-explosion limitation) and is regarded as a dangerous emergency. The degrees of danger and the corresponding measures are shown in Table 1.

3.3. Ventilation Systems. In the field, gas drainage is the primary tool used to reduce the gas content of the coal to be below predetermined threshold limits [21]. Generally, as a response to the gas emission problem, a methane drainage system includes a surface suction plant and pipe reticulation of the gas to the surface [22]. However, it is impractical for physical experiments to drainage gas by earth surface before gas outbursts. Thus, gas drainage after coal and gas outbursts

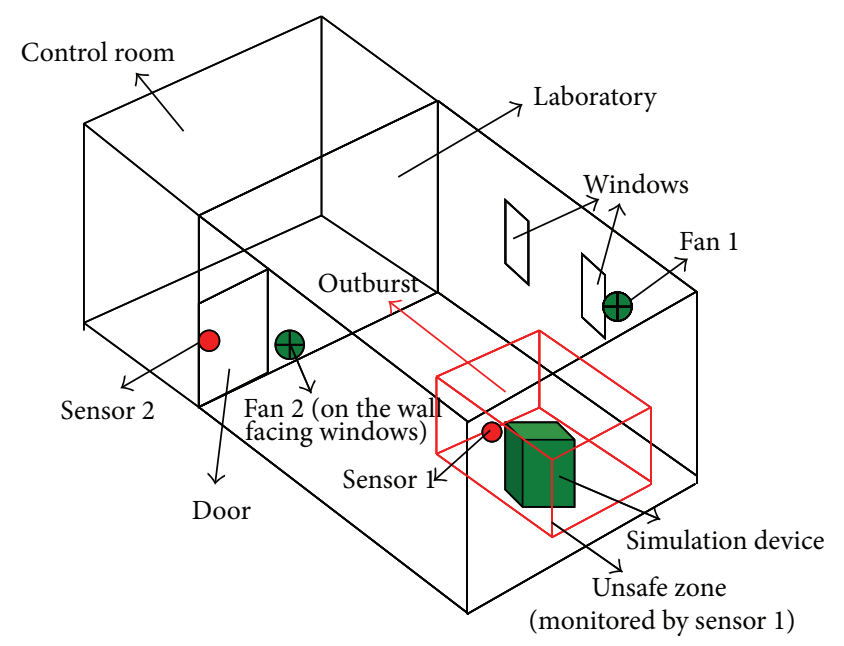

FIgURE 8: Locations of sensors, fans, and monitoring areas in the space.

are a feasible path to reduce the gas content. In our case, the ventilation system is composed of two fans. The powers of fans are estimated as follows:

$$
\begin{gathered}
V_{x}=37.5 \mathrm{~m}^{3} ; \quad V_{y}=208.656 \mathrm{~m}^{3} ; \\
V_{1}=V_{x}(1 \%-0.025 \%) \approx 0.366 \mathrm{~m}^{3} ; \\
V_{2}=V_{x}(4 \%-1 \%) \approx 1.125 \mathrm{~m}^{3} ; \\
V_{3}=V_{y}(1 \%-0.025 \%) \approx 2.034 \mathrm{~m}^{3} ; \\
K=\frac{q}{p}=0.54 \\
q_{1}=N_{1} \times \frac{V_{1}}{t_{1}}=8 \times \frac{0.366}{20}=0.146 \mathrm{~m}^{3} / \mathrm{s} \\
q_{2}=N_{2} \times \frac{V_{2}}{t_{2}}=6 \times \frac{1.125}{20}=0.34 \mathrm{~m}^{3} / \mathrm{s} ; \\
q_{3}=N_{3} \times \frac{V_{3}}{t_{3}}=4 \times \frac{2.034}{30}=0.21 \mathrm{~m}^{3} / \mathrm{s}
\end{gathered}
$$

where $V_{x}$ is the area monitored by Sensor 1 while the monitoring area of Sensor 2 is $V_{y}$, and $V_{1}, V_{2}$, and $V_{3}$ are the gas volumes under Danger 1, Danger 2, and Danger 3, respectively. Under Danger 1 and Danger 2 , the work times $t_{1}$ and $t_{2}$ of the ventilation system are $20 \mathrm{~s}$, while, for the whole room, the ventilation system reduces Danger 3 effectively 

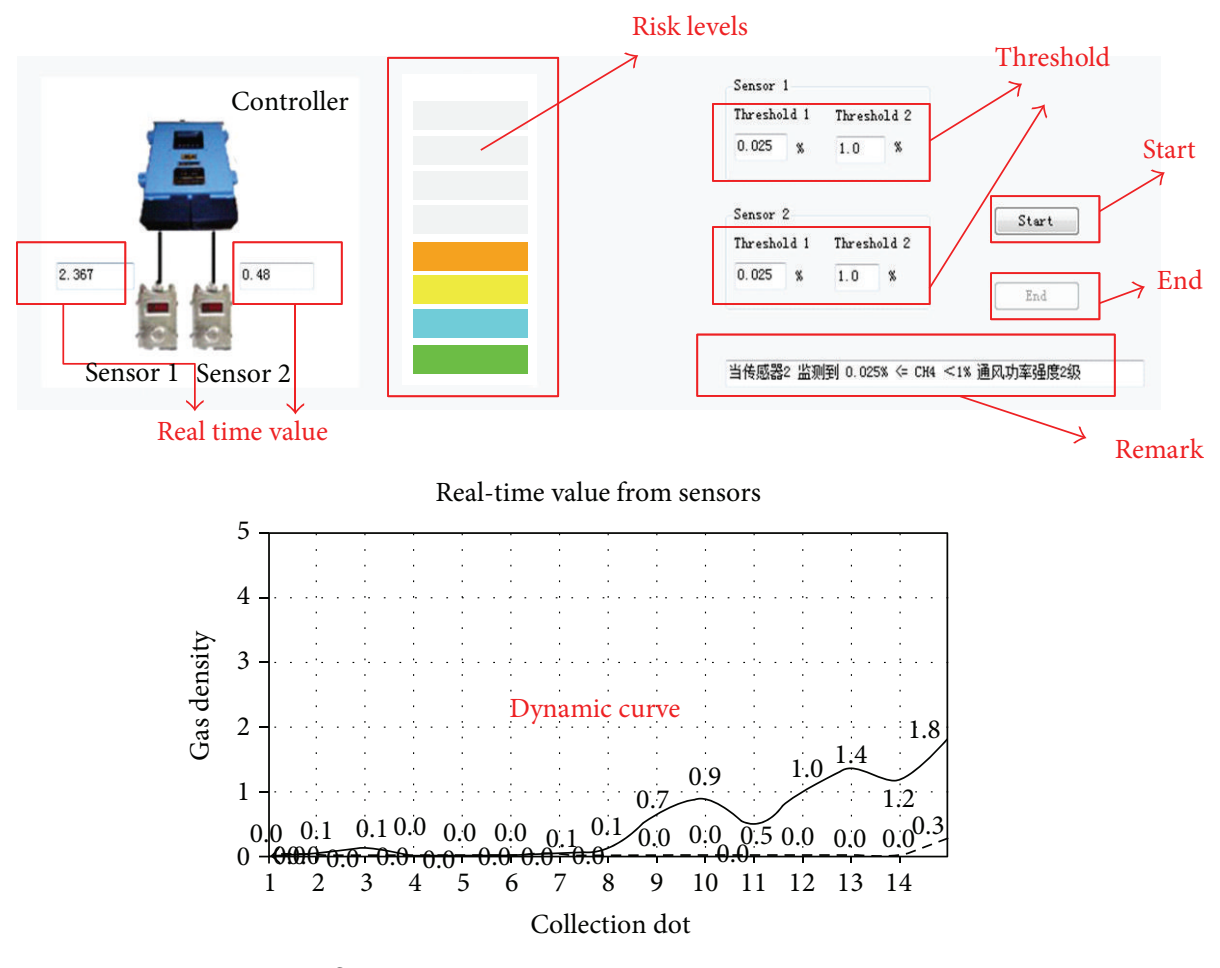

- Sensor 1
-- Sensor 2

FIGURE 9: Interface of software.

within $30 \mathrm{~s}\left(t_{3}\right)$. However, gas expelled through the fans is not pure methane gas. Thus, we introduce a ventilation coefficient $N$ which compensates for incomplete gas transpiration. In consideration of the spread of gas, $N_{1}=8, N_{2}=6$, and $N_{3}=4$. These values are roughly estimated by gas volume as the time elapsed during the gas outburst experiment. For example, $N_{3}=4$ means that at that moment the volume of gas occupied $25 \%$ of the whole room. Under Danger 1, Danger 2, and Danger 3 the ventilation levels are $q_{1}, q_{2}$, and $q_{3}$, respectively. The energy efficiency value of the fans is $K$. The previous calculation suggests that Fan 1 (rating $20 \mathrm{~W}$ and $30 \mathrm{~W}$ ) and Fan 2 (rating $30 \mathrm{~W}$ ) can comprise the ventilation system. We installed Fan 1 at the window facing the simulation device in order to expel the gas around the simulation device. Fan 2, which mainly expels the gas in the laboratory, was located at the door between the control room and the laboratory. At Ventilation 1 the system switches on Fan 1 at the $20 \mathrm{~W}$ rating; at Ventilation 2, Fan 1 is switched on at the $30 \mathrm{~W}$ rating; under Danger 3, both Fan 1 (rating $20 \mathrm{~W}$ ) and Fan 2 (rating $30 \mathrm{~W}$ ) are turned on.

3.4. Design of Software. The software produced by VC++ displays real-time data and dynamic curves, whose interface is divided into two parts (Figure 9). The upper part is composed of three parts: the left one shows the real-time gas concentration value; in the middle, levels of danger are detected (green to red means low to high); in the right part a threshold can be set. Generally, there is a default but the threshold can also be set by hand. The lower part shows the gas concentration value curve for the time elapsed by Sensor 1 and Sensor 2.

\section{Results and Discussion}

In order to test this monitoring and control system, coal and gas outbursts (Danger 1-Danger 3) with a load application of $2.4 \mathrm{Mpa}, 4 \%$ water content, and gas pressure increment $(0.5,1$, and $1.5 \mathrm{Mpa})$ are applied. The condition of Danger 4 is a load application of $3.6 \mathrm{Mpa}, 0 \%$ water content, and gas pressure of $1.5 \mathrm{Mpa}$. The purpose of the experiments is to investigate the performance of the monitoring and control system under four situations of increased intensity of coal and gas outburst. Dangers 1-4 indicate that the relative outburst intensities (outburst coal as a percentage of the whole coal mass) are $0,19.11,26.11$, and $38.7 \%$, respectively.

4.1. Comparison of Cases with and without the System under Dangers 1-4. The corresponding performances of the monitoring and control system are shown in Figures 10(a)-10(d).

Figure 10(a), Danger 1: no outburst means that the gasonly emission, without being pushed, contributes to the gas content in the laboratory. The gas concentration around the device shows dramatically increasing content. From $t=0-4$ seconds, Ventilation 1 is activated. Once the value exceeds $1 \%$ at Sensor 1 (about the 4th second), Ventilation 2 is activated. And at about $t=5$ seconds, Ventilation 3 is also activated by Sensor 2. It can be seen that the gas content recovers to normal status in $t=15$ seconds. By contrast, without 


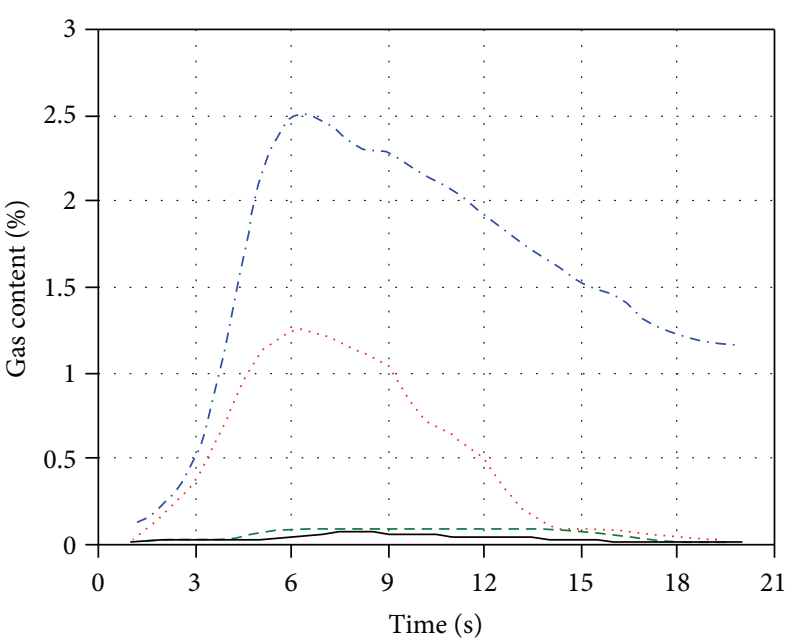

(a)

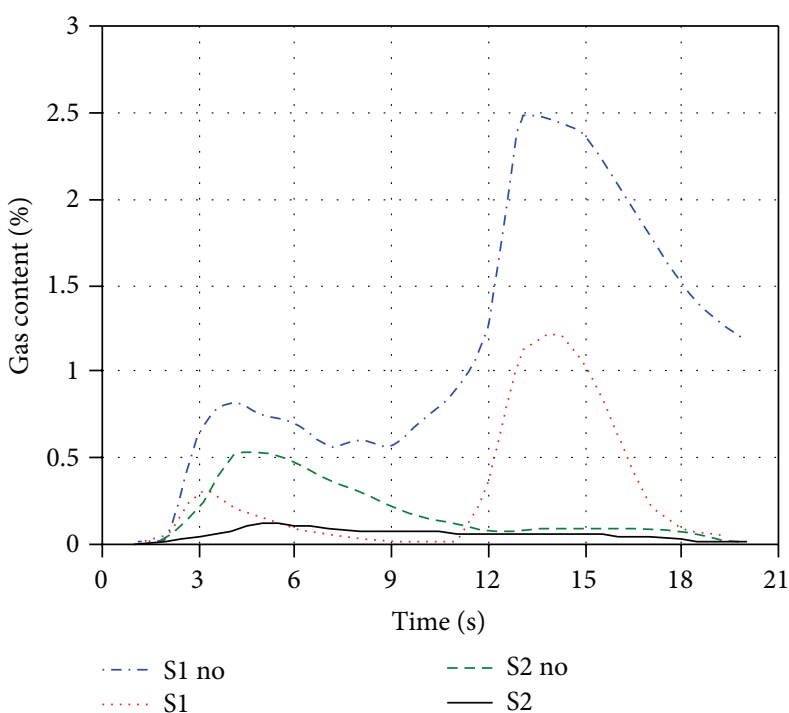

(c)

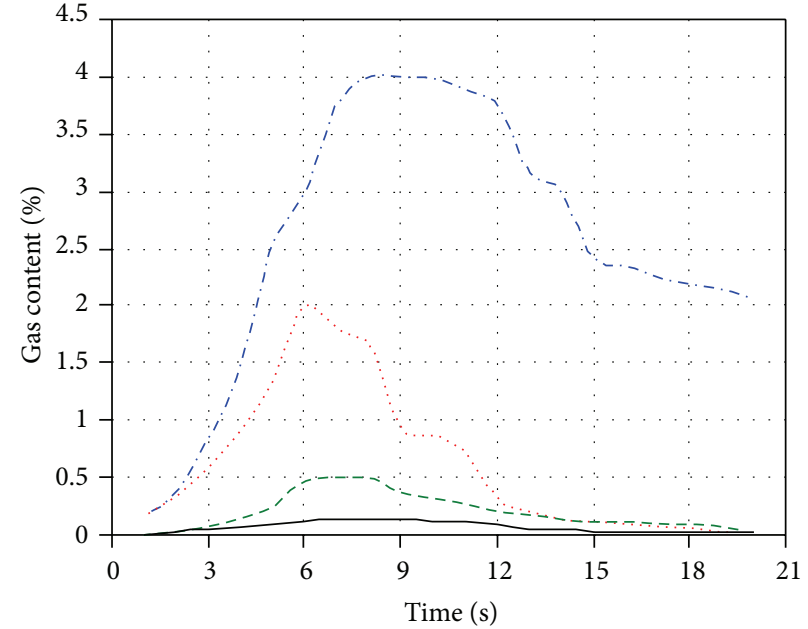

(b)

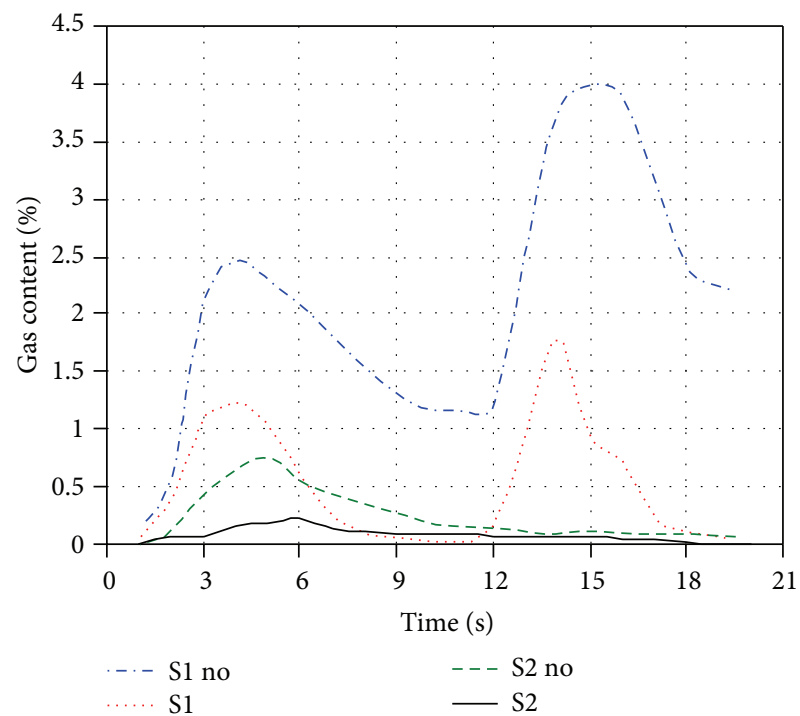

(d)

Figure 10: Gas content curves versus time. S1 no: without ventilation (Sensor 1); S1: ventilation (Sensor 1); S2 no: without ventilation (Sensor 2); S2: ventilation (Sensor 2).

ventilation measures, the curve (Sensor 1) is still at a high level for over 20 seconds and it takes 17 seconds to reduce the gas content in the Sensor 2 monitoring area. Figure 10(b), Danger 2: a low intensity of coal and gas outburst contributes to the gas content around the unsafe zone more swiftly than Danger 1. Within the 1st second, the threshold of $0.025 \%$ is exceeded. In order to control the gas content level, Ventilation 1 is activated. At about the 4th second, Ventilation 2 is activated for the threshold of $1 \%$. Sensor 2 shows that the gas content is between 0.025 and $1 \%$ after the 3 rd second. Once Ventilation 3 is switched on, the gas concentration curve seems to become more flat in 13 seconds. On the contrary, without the help of fans the blue curve reaches the limit of Sensor $1(4 \%)$ at around 9 seconds. Sensor $2(0.5 \%)$ is also at a high level at about the 7th second. In Figures 10(c) and $10(d)$, an increase of the outburst not only improves the gas content but also pushes the gas concentration away from the outburst caliber. Figure 10(c), Danger 3: a high intensity coal and gas outburst push the concentrated gas closer to the monitoring point of Sensor 2. Thus, the gas content around the simulation device seems to be lower than under Danger 2. About 12 seconds later, the curve has a second peak because of the back spread of gas. In the first stage (1-11 seconds), only Ventilation 1 works for the $0.025 \%$ threshold. At the same time, Ventilation 3 is also activated. Thus, it is found that the gas content around Sensor 2 is controlled gradually. However, after the 12th second the spread of gas not only from the unsafe zone but also from the area of Sensor 2 improves the gas content in the unsafe zone again. Both Ventilation 2 and Ventilation 3 work for gas drainage. If ventilation measures are not installed, the staff may avoid the first gas content concentration but ignore the second peak of 
gas content, which is a huge potential hazard. Figure 10(d), Danger 4: high gas pressure and high gas adsorption caused by low water content lead to the highest intensity of coal and gas outburst in our case. The gas content around the simulation device increases suddenly to more than $0.025 \%$, which activates Ventilation 1 . However, the gas content jumps to over 1\% at the 3rd second, and thus Ventilation 2 has to be activated. Within 8 seconds, the gas content is controlled swiftly. By contrast, Ventilation 3 also works at about the 3 rd second but does not stop until the 18th second. After the 12th second, the spread of gas induces another peak of gas content. So Ventilation 2 has to be activated again. Considering that there is no drainage device, the peaks of gas content obviously increase and remain at $2 \%$ even after 20 seconds. Especially, after the 12th second, the spread of gas leads to a gas content (Sensor 1 ) of approximately $5 \%$, which is greater than $4 \%$ (explosive limitation) and is absolutely dangerous. In order to investigate error or deviation of the experiment and monitoring and control system, two groups of replicable experiments were carried out under the same condition. Part of the results, for example, is the relative error of the two groups of experiments for Danger 1 shown in Figure 11 and the correlation between the two groups of experiments for Danger 1 shown in Figure 12. In addition, all of the results of the replicable experiments are summarized in Table 2.

4.2. Relationship between Relative Outburst Intensities and Gas Content in Temporal Domains. Gas spread trends under different degrees of danger are investigated by 3D fitting from Matlab as shown in Figure 11. Heavy outburst intensities mean that more coal and gas from an outburst are ejected further away from the device [8-10]. In other words, the centre of gas would be pushed further from the device. Figure 13(a) demonstrates what happens when the gas center after the outburst is around the outburst caliber or is close to the monitoring point $S 1$ (insufficient power to push the coal and gas away; here the intensity $<25 \%$ ), while the stronger outburst intensity induces a higher gas concentration peak ( $t$ $=6-12 \mathrm{~s})$; once the gas centre is far away from the monitoring point like Dangers 3-4 the gas concentration is not high in the beginning (enough power to push the coal and gas away; here the intensity $>25 \%$ ). As time elapses, the rebounds of gas improved the gas content again in S1 (it peaks at $t=14-$ 18 s). In Figure 13(b), because the gas center is always within the range of S2, the gas content increases with increments of the intensity of outburst. And the peak of gas content appears earlier at heaver intensity $(t=3-7 \mathrm{~s})$ than at lower intensity $(t=7-12 \mathrm{~s})$. Thus, it could be considered that the gas concentrations at some points are affected by the intensity of outburst and positions of these points. The positions should not be ignored as key factors.

\subsection{Comparison between the Real Scene and Numerical Model.}

The general method used is to install the gas sensor probes mounted in the laboratory without considering the tracking of gas distribution but only giving a warning when the gas content threshold is exceeded. Thus, there are no other

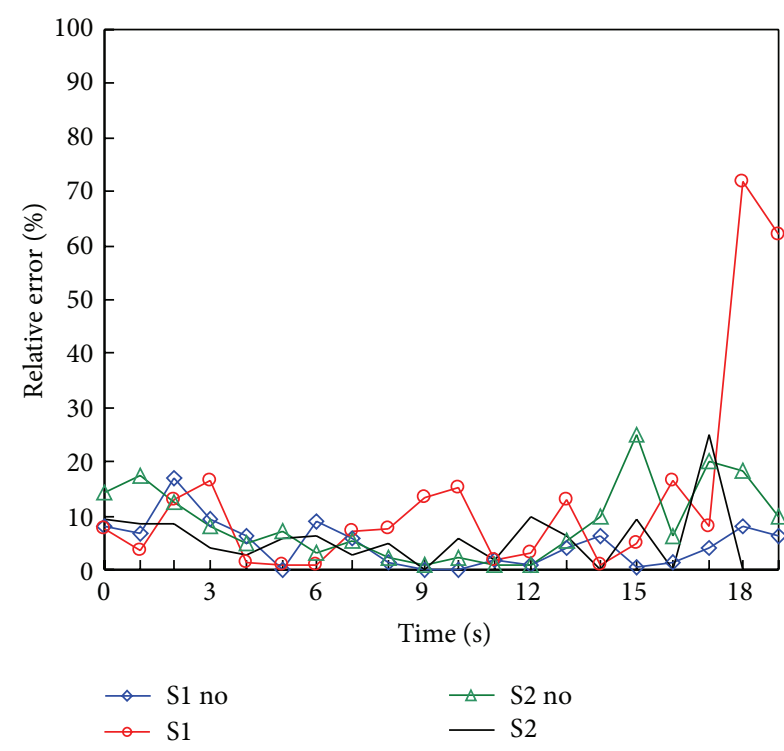

FIGURE 11: Relative error of two groups of experiments for Danger 1.

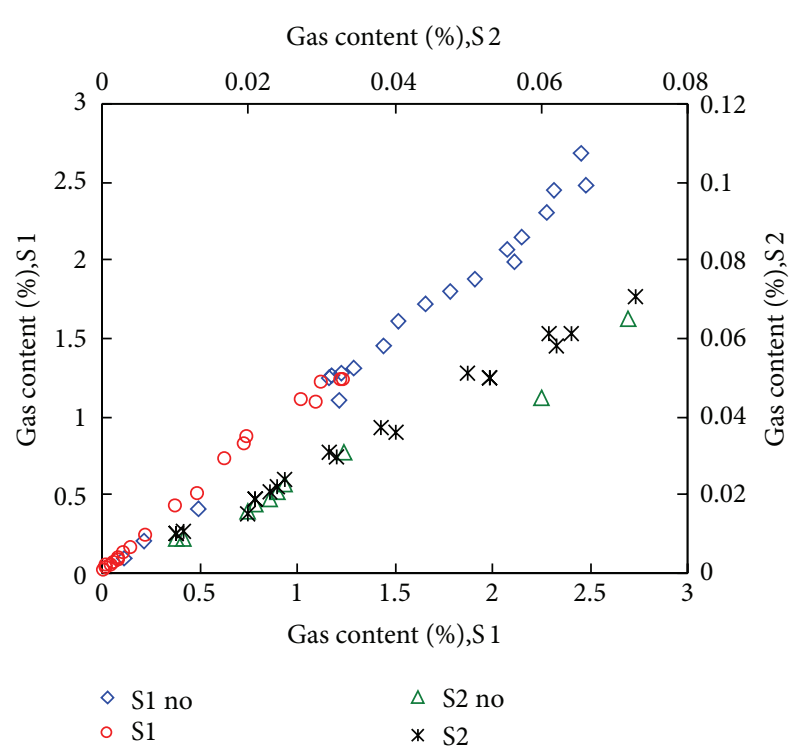

FIGURE 12: Danger 1: S1 no, 0.9884; S1, 0.9933; S2 no, 0.9889; S2, 0.9935 (S1 no: without ventilation (Sensor 1); S2 no: without ventilation (Sensor 2)).

comparative results from existing systems in the literature. In order to determine the air flow and power, Fluent software with numerical simulation of gas outbursts was used to demonstrate the concentration distributions and velocity distributions (Danger 1) [23]. A geometric model was built using Gambit software. The type of grid cell was Tet/Hybird and the type of tetrahedral mesh in space was T grid, which generated a total of 142,209 grid elements. The uncoupled segregated solution method was used for the solution. From Figure 14(a), in the center of the laboratory the gas concentration was close to $3.5 \%$ and the direction of migration was towards the top left $(t=3 \mathrm{~s})$. The gas concentration becomes lower in the area on 
TABLE 2: Results of average relative error and correlation between two groups of tests.

\begin{tabular}{lccccccc}
\hline & \multicolumn{3}{c}{ Average relative error } & \multicolumn{3}{c}{ Correlation } \\
& S1 no & S1 & S2 no & S2 & S1 no & S1 & S2 no \\
\hline Danger 1 & $4.87 \%$ & $13.42 \%$ & $8.74 \%$ & $5.56 \%$ & 0.9884 & 0.9933 & 0.9889 \\
Danger 2 & $8.93 \%$ & $11.23 \%$ & $9.23 \%$ & $4.56 \%$ & 0.897 & 0.923 & 0.976 \\
Danger 3 & $12.12 \%$ & $8.92 \%$ & $11.23 \%$ & $6.7 \%$ & 0.924 & 0.913 & 0.962 \\
Danger 4 & $3.45 \%$ & $9.23 \%$ & $12.5 \%$ & $16.54 \%$ & 0.945 & 0.942 & 0.965 \\
\hline
\end{tabular}

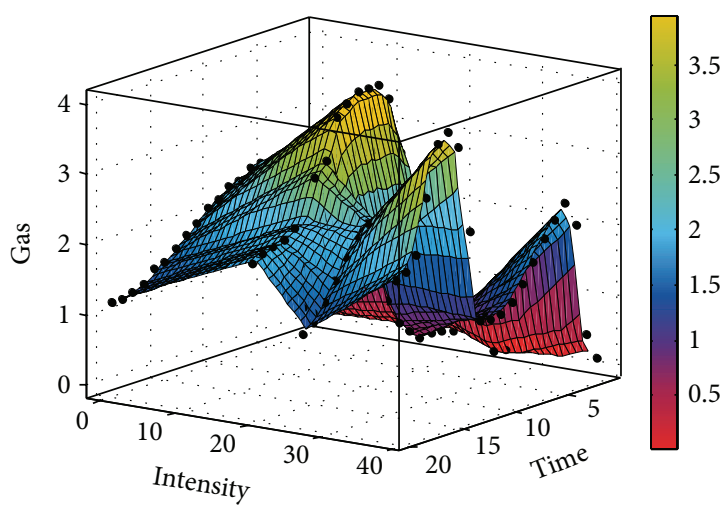

- Gas versus time, intensity

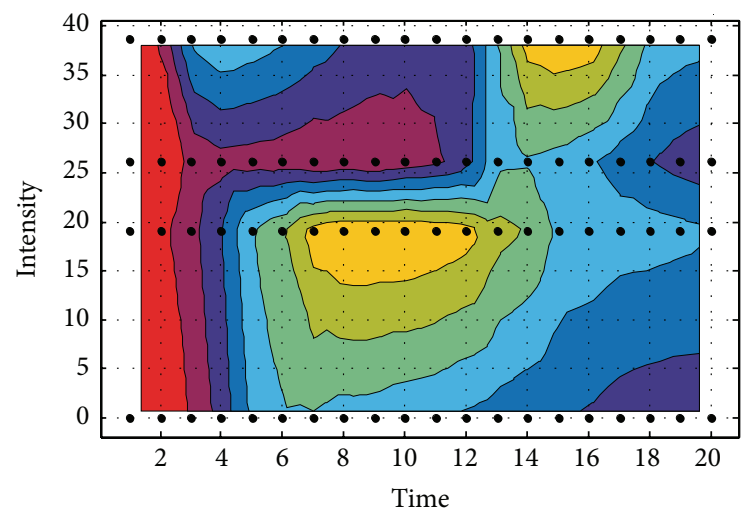

- Gas versus time, intensity

(a) $\mathrm{S} 1$

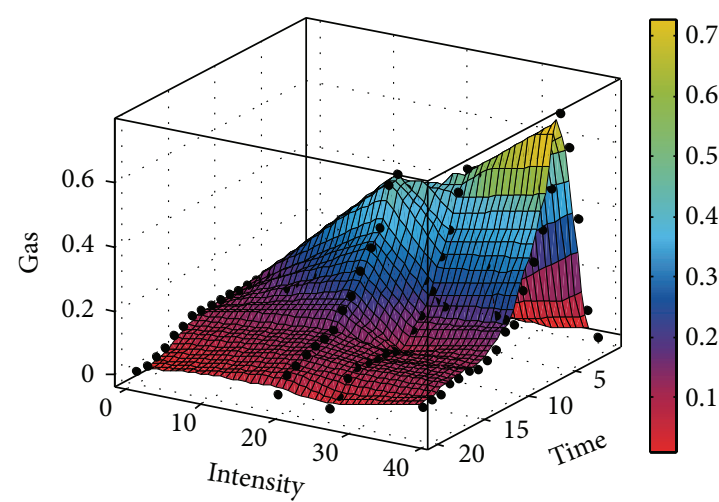

- Gas versus time, intensity

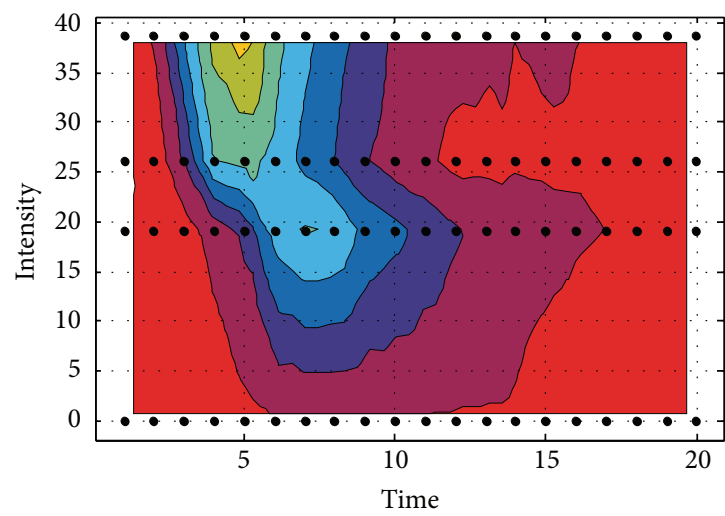

- Gas versus time, intensity

(b) $\mathrm{S} 2$

FIGURE 13: Gas spread trends under different degrees of danger for S1 and S2. Gas: gas content (\%); time (seconds); intensity: relative outburst intensities (\%).

the left, while in the area of S2 a concentration zone $(0.25 \%)$ appears in Figure 14(b) $(t=30 \mathrm{~s})$. By comparing Figures 12 and 10(a), the peak in the real scene is at the 6th second, when it has a value of $2.5 \%$, and then decreases as time elapses for S1. The gas value of S2 is $0.25 \%$ at the 30 th second while the peak of the monitoring data is $0.2 \%$ at the 15 th second. The trends generally agree with one another.

4.4. Evaluation of Our System and Traditional System. The selection of the optimal mitigation strategy is based on evaluation of the economic efficiency of the alternatives, which is called cost-benefit analysis (CBA) [24-26]. Qualitative (nonmonetary) criteria such as environmental and social impacts are not included in the CBA [27]. The principle of CBA is to compare the benefits and costs of alternatives over a period of time. The alternatives are compared against a reference option (present state or "do-nothing" option) and all future benefits $B i$ and costs $C i$ are discounted, that is, transformed to present value. The discount rate for public investments is c. $2-4 \%$ (3\% in our study) [28, 29]. Two strategies A and B are compared as follows in Table 3:

(A) installation of traditional warning system and evacuation,

(B) construction of our monitoring and control system. 


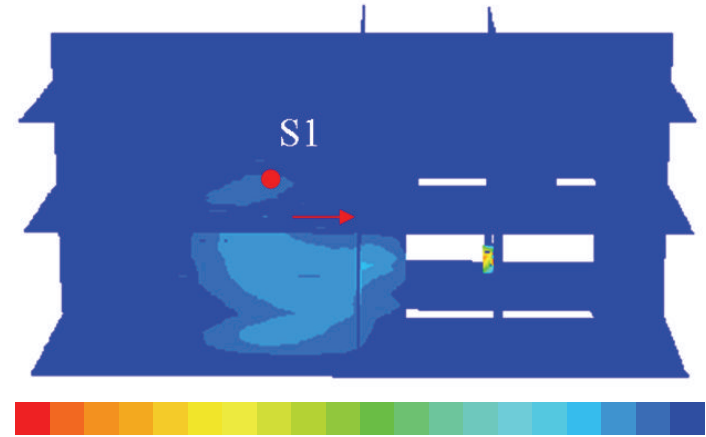

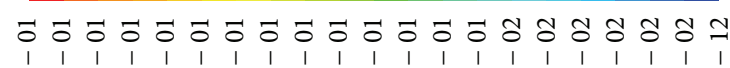

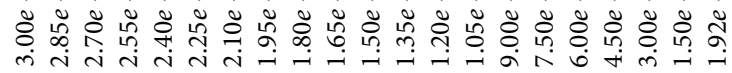

$Z \quad$ Contours of mole fraction of $\mathrm{ch} 4($ time $=3.0000 e+00)$ Dec. 28,2009

$Y-X$ Fluent 6.2 (3D, segregated, spe, ske, unsteady)

(a) Distribution of gas concentration $(t=3 \mathrm{~s})$

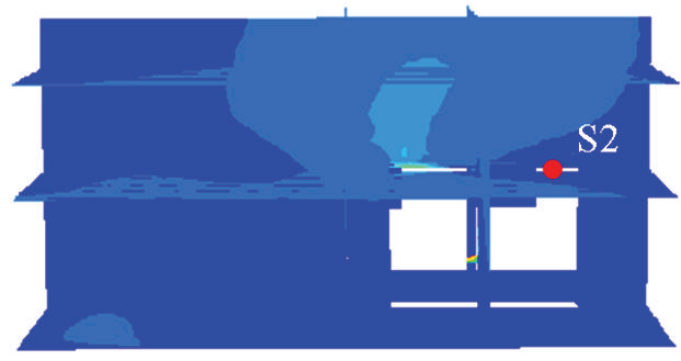

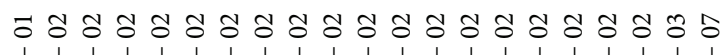

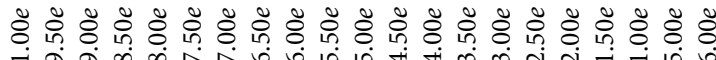

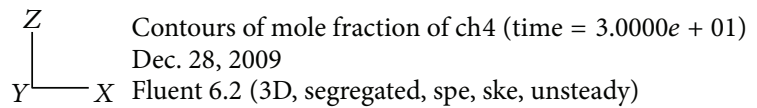

(b) Distribution of gas concentration $(t=30 \mathrm{~s})$

Figure 14: Numerical results.

TABLE 3: Calculation of cost-benefit analysis factors.

\begin{tabular}{lccc}
\hline & Strategy A (euros) & Strategy B (euros) & Do nothing (euros) \\
\hline Initial cost & 1500 & 1600 & 0 \\
Cost in next year & 6480 & 6782 & 6000 \\
Expected damages in next year & 710 & 0 & 2000 \\
Benefits in next year & 1290 & 2000 & 0 \\
\hline
\end{tabular}

The time horizon is 5 years (service life: 5 years) and the interest rate is $3 \%$.

\section{Remarks}

Initial Cost. Consider the following:

(A) hardware (sensors, computer, and data collector); human cost;

(B) hardware (sensors, computer, data collector, and fans); human cost;

(C) nothing.

Cost in Every Year. Consider the following:

(A) 24 repetitions of the experiment (material cost, energy changes, and human salary);

(B) 24 repetitions of the experiment (material cost, more energy changes (fan operation), and human salaries);

(C) 24 repetitions of the experiment (material cost, less energy changes (no monitoring system); and human salaries).

Expected Damages in Every Year. Consider the following:

(A) six repetitions of the heavy intensity outburst (probability of $50 \%$ failure) meaning 1 or $4 \%$ gas warning threshold is exceeded and people are evacuated; the damages are equal to the cost of the experiment;

(B) six repetitions of the heavy intensity outburst (no failure) because of our drainage system;

(C) suppose these heavy intensity outburst experiments induce one staff injury event (damages include the cost of the experiment plus medical fees).

In addition, there is no consideration of the cost of human death, simulated equipment maintenance fees, unavoidable incidents, and opportunity cost.

Total Net Present Value of Benefits. Consider the following:

$$
\begin{aligned}
& B_{A}=\sum_{i=1}^{5} \frac{B_{A i}}{(1+r)^{i}}=\sum_{i=1}^{5} \frac{1290}{(1+0.03)^{i}}=5907.822, \\
& B_{B}=\sum_{i=1}^{5} \frac{B_{B i}}{(1+r)^{i}}=\sum_{i=1}^{5} \frac{2000}{(1+0.03)^{i}}=9159.414, \\
& B_{\mathrm{no}}=\sum_{i=1}^{5} \frac{B_{\mathrm{noi}}}{(1+r)^{i}}=\sum_{i=1}^{5} \frac{0}{(1+0.03)^{i}}=0 .
\end{aligned}
$$


Total Net Present Value of Costs. Consider the following:

$$
\begin{aligned}
C_{A} & =1500+\sum_{i=1}^{5} \frac{C_{A i}}{(1+r)^{i}}=1500+\sum_{i=1}^{5} \frac{6480}{(1+0.03)^{i}} \\
& =31176.5 \\
C_{B} & =1600+\sum_{i=1}^{5} \frac{C_{B i}}{(1+r)^{i}}=1600+\sum_{i=1}^{5} \frac{6782}{(1+0.03)^{i}} \\
& =32559.57, \\
C_{\mathrm{no}} & =\sum_{i=1}^{5} \frac{C_{\mathrm{no} i}}{(1+r)^{i}}=\sum_{i=1}^{5} \frac{6000}{(1+0.03)^{i}}=27478.24 .
\end{aligned}
$$

Benefit-Cost Ratios. Consider the following:

$$
\begin{gathered}
\frac{B_{A}}{C_{A}}=\frac{5907.822}{31176.5}=0.1895 \\
\frac{B_{B}}{C_{B}}=\frac{9159.414}{32559.57}=0.281305 .
\end{gathered}
$$

Total Net Present Value. Consider the following:

$$
\begin{aligned}
B_{A}-C_{A} & =5907.822-31176.5=-25268.7, \\
B_{B}-C_{B} & =9159.414-33559.57=-23400.2, \\
B_{\mathrm{no}}-C_{\mathrm{no}} & =0-27478.24=-27478.24 .
\end{aligned}
$$

From the analyses above, we know that Measure $B$ is preferable according to these criteria and both measures are preferable to the do-nothing option.

4.5. Application Procedure of Our System in Other Laboratories. In order to reproduce the strategy of our study in other laboratories, the general procedure of designing this system should be emphasized as follows:

(1) identify all possible scenarios (dangers);

(2) identify exposed people and objects under all the scenarios;

(3) identify and assess the environment, for example, the room size;

(4) establish a set of possible strategies, for example, fan drainage (our monitoring and control system);

(5) determine costs of strategies (over entire life time);

(6) assess expected damages for all scenarios and all strategies;

(7) determine benefit-cost ratio for all strategies for the evaluation of strategies.

\section{Conclusions}

In the paper, we developed a simple gas monitoring and control system to reduce the danger levels for coal and gas outburst experiments in the laboratory. The system not only utilizes continuous cycle monitoring and sensor fusion for the enhancement of accurate warning but also, considering different degrees of danger, automatically selects the appropriate ventilation measures to reduce the increasing gas content. This study introduces the components, design principles, work process, and ventilation effects of the system. We believe the system can play an important role in not only the safety of staff but also the research on gas spreading during minioutburst experiments. Admittedly, it should be noted that this study simplifies some conditions; for instance, methane concentration values may be affected by the intrusion of air into the test room. Also, different temperatures and air pressures cause diversification of the gas concentration velocity, affecting the reliability of the system. Despite its preliminary character, this study clearly indicates that developing this monitoring and control system has huge potential for the safety of minioutburst experiments. In the future, temperature sensors and gas flow rate sensors will be added to the monitoring and control system for more accurate work.

\section{Conflict of Interests}

The authors declare that there is no conflict of interests regarding the publication of this paper.

\section{Acknowledgments}

The research was supported by the Opening Fund of the State Key Laboratory of Coal Mine Disaster Dynamics and Control (Chongqing University) (2011DA105287-KF201312) and supported in part by the General Project of the National Natural Science Foundation of China (Grant no. 51304255).

\section{References}

[1] A. A. Skoczyński, "Communication concerning sudden coal and gas outburst conducted with use of a model in the laboratory of sudden outbursts in the Mining Institute of the Russian Academy of Sciences," Ugolnik, pp. 10-39, 1953 (Russian).

[2] V. S. Kravchenko, "On the nature and mechanism of coal and gas sudden outbursts," Iz. AN SSSR, Otd. tekhn. nauk, vol. 6, pp. 101-108, 1955.

[3] J. G. Botham, "Association of gases with coal laboratory outburst tests on solid coal specimens," Fuels Div. Tech. Memo. 75/57 OCG, Department of Mines \& Technical Surveys, Mines Branch, Ottawa, Canada, 1957.

[4] T. Kuroiwa and T. Tashiro, "Experimental study on coal pulverisation and gas emission in a moment of outbursts of gas and coal," Journal of Japanese Mining, vol. 76, no. 862, pp. 227-233, 1960.

[5] H. T. Patching and J. C. Botham, "research and control of sudden outbursts of coal and gas in Canada," in Proceedings of the International Conference Problems of Sudden Outbursts of Gas and Rock, Leipzig, Germany, 1966.

[6] J. A. Hargraves and R. W. Upfold, "Aspects of laboratory simulations of instantaneous outbursts," in Proceeding of the 21st International Conference Safety in Mines Research Institutes, pp. 129-137, Sydney, Australia, October 1985. 
[7] J. Bodziony, A. Nelicki, and J. Topolnicki, "Results of laboratory investigations of gas and coal outbursts," Archives of Mining Sciences, vol. 94, no. 3, pp. 581-591, 1989.

[8] J. Topolnicki, Rock and Gas Outbursts-Laboratory Research and Mathematical Modeling, vol. 67, IGSMiE, Krakow, Poland, 1999, (Polish).

[9] S. K. Choi and B. Wu, "Laboratory study of coal properties and outburst simulation-application to gas drainage, outburst prediction, control and management," ACARP Project C13012 Final Report, December 2008.

[10] W.-Z. Wang, Y.-Q. Tao, J. Xu, and S.-J. Peng, "Simulation of coal and gas outburst with different gas pressure," Journal of Chongqing University, vol. 33, no. 3, pp. 82-86, 2010.

[11] J. Xu, D. Liu, G.-Z. Yin, Q. Lu, and S.-J. Peng, "Simulation experiment of coal and gas outburst under non-uniform load," Journal of the China Coal Society, vol. 37, no. 5, pp. 836-842, 2010.

[12] J. Xu, D. Liu, S. Peng, X. Wu, and Q. Lu, "Experimental research on influence of particle diameter on coal and gas outburst," Chinese Journal of Rock Mechanics and Engineering, vol. 29, no. 6, pp. 1231-1237, 2010.

[13] J. S. Ni, T.-Y. Liu, J. Chang et al., "A low cost multiplexed $1.331 \mu \mathrm{m}$ spectroscopic remote methane sensor system," Fundamental Problems of Optoelectronics and Micro-Electronics III, vol. 6595, pp. 65952Z1-65952Z15, 2007.

[14] Y. Shimose, T. Okamoto, A. Maruyama, M. Aizawa, and H. Nagai, "Remote sensing of the seasonal variation in column abundance of atmospheric CHB4B," IEEE Photonics Technology Letters, vol. 3, no. 1, pp. 386-387, 1991.

[15] S. T. Wang, J. Liu, R.-S. Che, and Y.-T. Wang, "A methane gas sensor with optic fiber based on frequency harmonic detection technique," Journal of Applied Optics, vol. 25, no. 2, pp. 44-47, 2004.

[16] J. Ni, J. Chang, T. Liu, Y. Li, Y. Zhao, and Q. Wang, "Fiber methane gas sensor and its application in methane outburst prediction in coal mine," in Proceedings of the 1st Asia-Pacific Optical Fiber Sensors Conference (APOS '08), pp. 1-4, IEEE, November 2008.

[17] W. Nie, J. Xu, and Y. Liu, "Design of automatic closed system about gas outburst monitor and its role of the reducing security cost," in Proceedings of the 2nd International Conference Mine Hazards Prevention and Control, pp. 538-543, Atlantis Press, Paris, France, 2010.

[18] J. Xu, Y. Tao, G. Yin, S. Li, and W. Wang, "Development and application of coal and gas outburst simulation test device," Chinese Journal of Rock Mechanics and Engineering, vol. 27, no. 11, pp. 2354-2362, 2008.

[19] Y. D. Jiang, W. X. Zhou, S. X. Mei et al., "Bede mine ground stress field testing and distribution," Journal of Mining Safety \& Environmental Protection, vol. 38, no. 1, pp. 1-3, 2011.

[20] Work Safety State Administration, National Coal Mine Safety Supervision Bureau, Coal Mine Safety Regulations [Z], vol. 3, pp. 18-32, 2011.

[21] B. Belle, "Real-time air velocity monitoring in mines-a quintessential design parameter for managing major mine health and safety hazards," in Proceedings of the Coal Operators' Conference, University of Wollongong, 2013.

[22] P. Eade, "Case study outburst and gas management," in Proceedings of the Coal Operators' Conference, p. 199, February 2002.

[23] W. Xin, "Experimental research on simulation of coal and gas outburst in various particle size," Safety Technology \& Engineering, pp. 39-40, 2010, (English abstract).
[24] A. K. Gupta and P. J. Moss, Eds., Guidelines for Design of LowRise Buildings Subjected to Lateral Forces, CRC Press, 1993.

[25] S. R. Cellini and J. E. Kee, "Cost-effectiveness and cost-benefit analysis," in Handbook of Practical Program Evaluation, p. 493, 2010.

[26] S. J. Wholey, P. H. Hatry, and K. E. Newcomer, Handbook of Practical Program Evaluation, John Wiley \& Sons, New York, NY, USA, 2010.

[27] D. Weimer and A. Vining, Policy Analysis: Concepts and Practice, Pearson-Prentice Hall, Upper Saddle River, NJ, USA, 4th edition, 2005.

[28] J. K. Arrow and M. Kruz, Public Investment, the Rate of Return, and Optimal Fiscal Policy, Routledge, New York, NY, USA, 2013.

[29] K. J. Arrow and R. C. Lind, "Uncertainty and the evaluation of public investment decisions," Journal of Natural Resources Policy Research, vol. 6, no. 1, pp. 29-44, 2014. 

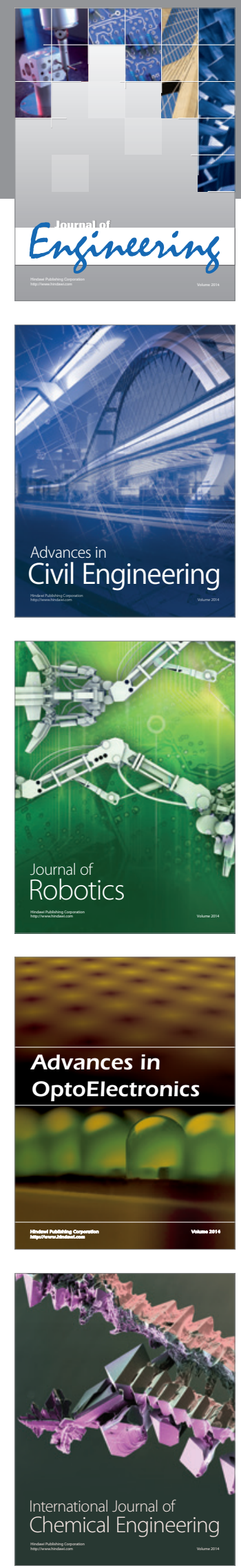

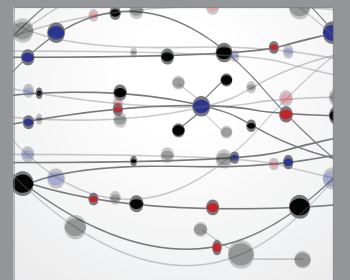

The Scientific World Journal
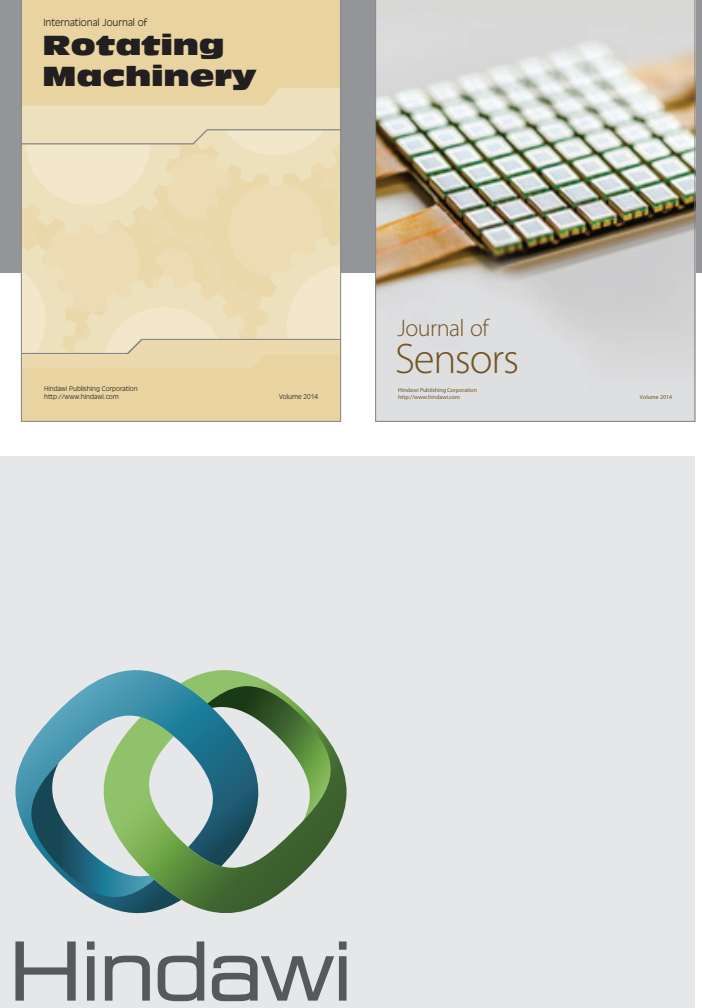

Submit your manuscripts at http://www.hindawi.com
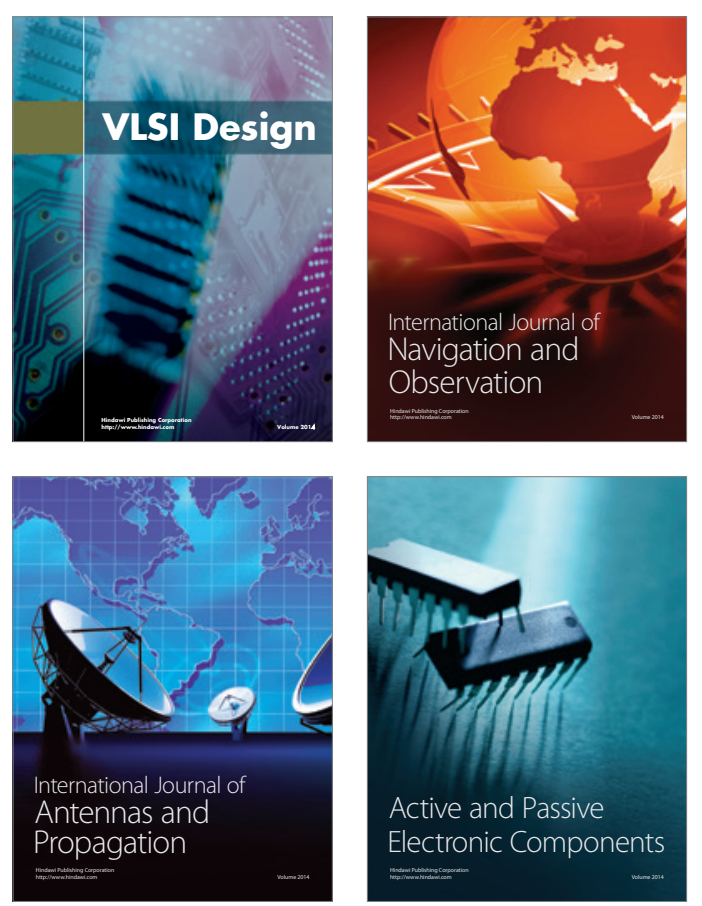
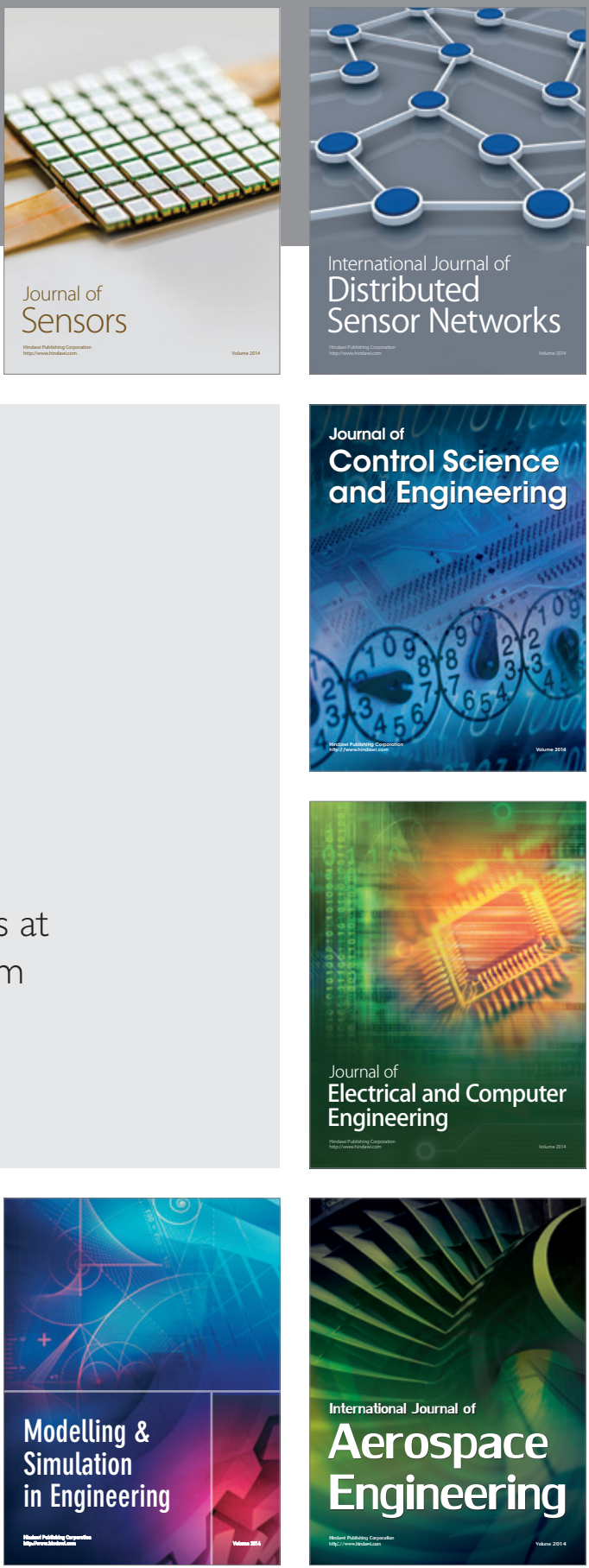

Journal of

Control Science

and Engineering
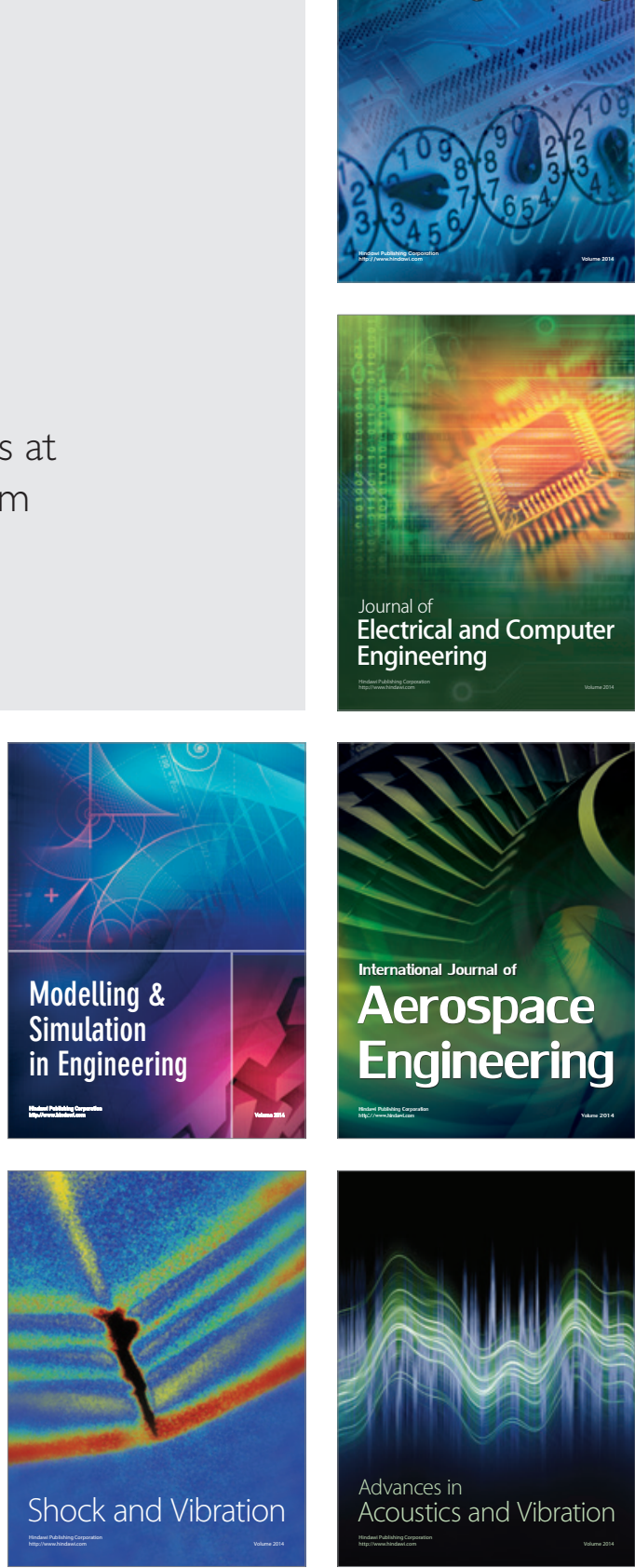